\title{
ACCESS TO HERITAGE: THE ROLE OF THE MALTESE NATIONAL CULTURAL HERITAGE AGENCY
}

\author{
KATYA MANISCALCO \\ Heritage Malta, Malta
}

\begin{abstract}
A small island in the Mediterranean, Malta is rich in culture and heritage architecture spanning several thousand years - from prehistory to Roman, Arab, Norman, Medieval, Knights of St John, French, British and modern Malta. Heritage Malta is the national agency that manages several historical buildings and sites, including sites inscribed on the World Heritage List ranging from the underground Hal Saflieni Hypogeum to the Megalithic Temples and the City of Valletta. The importance of preserving heritage buildings for all of humanity is widely accepted. Cultural heritage belongs to people from all walks of life, and each person has a right and responsibility to appreciate and conserve its universal values. Rendering sites accessible inherently implies a degree of impact; hence, this raises a number of questions: What is accessibility? What are the potential impacts and risks? Is physical accessibility a right in all cases? What solutions can be adopted to render cultural heritage accessible? This paper will focus on how Heritage Malta, through its various projects and interventions (past and future), is addressing its mission statement in rendering cultural heritage accessible to the wider public. Furthermore, the paper shall also highlight the benefits of having an agency setup managing multiple assets.
\end{abstract}

Keywords: Heritage Malta, accessibility, cultural heritage, values, society, public, World Heritage sites.

\section{INTRODUCTION}

Malta, being a small island in the centre of the Mediterranean Sea, is rich in history and culture spanning from Prehistory to Roman, Arab, Norman, Medieval, Knights of St John, French, British and modern Malta.

The Maltese agency, which takes care of cultural sites for both present and future generations, is Heritage Malta, which also ensures that all elements of cultural heritage entrusted to it are protected and made accessible to the public.

Heritage Malta is responsible for forty one (41) different heritage sites located all over the island, twenty-six (26) of which are open for visitors to enjoy on a daily basis. Seven (7) of these - the Megalithic Temples of Malta and the Hal Saflieni Hypogeum - are World Heritage sites, while several others are historical buildings located within the world heritage City of Valletta. Even though not all sites are open to the public, all have a high cultural significance.

One main objective of this paper is to describe one of Heritage Malta's primary roles which is "to bring culture closer to the people through facilitating interpretation and accessibility, both physical and intellectual depending on the needs of society and the government. Whether through temporary exhibitions, public lectures, heritage trails or other specialized events, the agency ensures that it lives up to the motto of safeguarding a future to our past" [1]. Another objective is to review the balance between the protection of heritage sites vis-a-vis the level of accessibility for visitors to experience and enjoy. Each individual will experience heritage sites in a unique manner and will create different memories, depending on his or her interests.

Three sites of different nature will be discussed, in order to give a brief overview of the different criteria that one comes across when dealing with cultural heritage. The sites, a 
Baroque palace, a prehistoric underground cemetery, and a prehistoric megalithic structure, will be described below. All three have a visitor centre, one within the site itself, one directly above it and one a few metres away.

\section{CASE STUDIES}

\subsection{Grandmaster's Palace in the City of Valletta}

The Grandmaster's Palace was one of the first buildings in the new city of Valletta founded by Grand Master Jean de Valette in 1566, a few months after the successful outcome of the Great Siege of Malta in 1565. The palace was subsequently enlarged and developed by successive Grandmasters to serve as their official residence. Later during the British period, it served as the Governor's Palace and was the seat of Malta's first constitutional parliament in 1921. The palace today is the seat of the Office of the President of Malta.

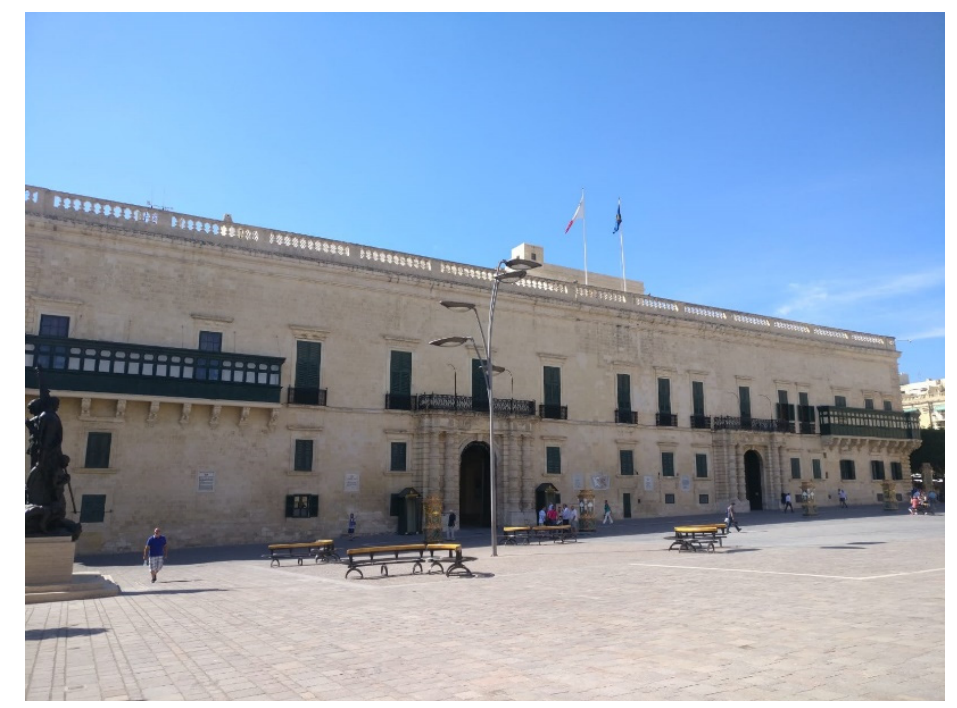

Figure 1: Grandmaster's Palace. (Source: Image courtesy of author.)

The Palace Armoury is one of the world's largest collections of arms and armour and is still housed in its original building. The Knights of St John were a unique brotherhood of resolute warrior monks. From Malta, their island stronghold, these combatant aristocrats from the noblest houses of Europe, carried out their relentless crusade against the Ottoman Turks in defence of the Catholic faith. The Palace Armoury is, therefore, certainly one of the most visible and tangible symbols of the past glories of the Sovereign Hospitaller Military Order of Malta.

Hence, both the State Rooms and the Armoury are the showpiece of the Presidential Palace sited at the heart of Malta's World Heritage capital city [2].

\subsection{Hal Saflieni Hypogeum in Paola}

The Hal Saflieni Hypogeum is an underground prehistoric burial site discovered in 1902 during construction works. This site is complex, made up of interconnecting rock-cut 
chambers set on three distinct levels. Earliest remains at the site date back to about $4000 \mathrm{BC}$, and the complex was used over a span of many centuries, up to circa $2500 \mathrm{BC}$. The uppermost level consists of a large hollow with burial chambers on its sides. This hollow was probably originally exposed to the sky and excavations in the early 1990s indicate that there may have also been a monumental structure marking the entrance.

A doorway leads to the Middle Level, which contains some of the best-known features of the Hypogeum such as the intricate red ochre wall paintings and the beautifully carved features that recall the architectural elements common in contemporary megalithic aboveground structures. The deepest of the three levels is known as the Lower Level, which is accessed down seven steps in the chamber popularly known as the "Holy of Holies" [3].

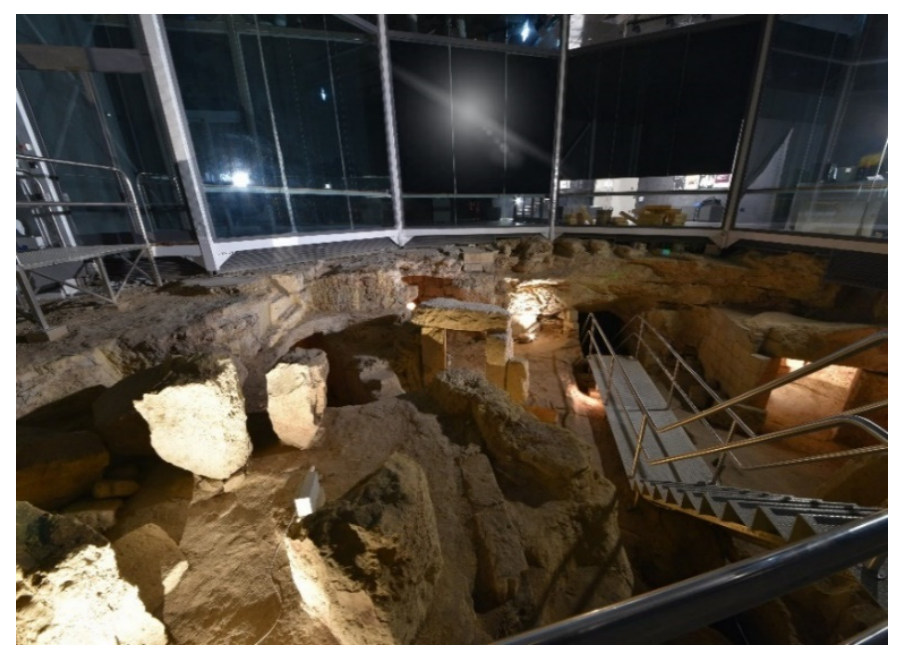

Figure 2: Hal Saflieni Hypogeum. (Source: Image courtesy of Heritage Malta.)

\subsection{Hagar Qim and Mnajdra Temples in Żurrieq}

Hagar Qim and Mnajdra Temples are located along the southwest coast of Malta, $500 \mathrm{~m}$ away from one another and some $2 \mathrm{~km}$ away from the village of Qrendi. Hagar Qim temples, standing at the top of a ridge, with the ground sloping away on three sides, has always been a conspicuous landmark.

The complex of Hagar Qim consists of one large building and two smaller separate structures. All three buildings are entirely constructed in Globigerina Limestone, a type of stone that outcrops in the immediate vicinity. The main building appears to have been created in a succession of building interventions during the fourth millennium $\mathrm{BC}$, resulting in an unusually irregular and complex ground plan.

Mnajdra consists of three main buildings. The earliest of the three is the small three-apsed structure, built around the mid-fourth millennium BC. The South Temple, which has a fourapsed plan, was constructed early in the third millennium BC whilst the Central Temple, similar in plan, was last to be built.

Unlike Hagar Qim Temples, the external walls here were built with Lower Coralline Limestone which outcrops naturally in the vicinity. A particular characteristic of this site is the orientation of the South Temple. This building is aligned with the rising position of the sun during the Equinoxes [4]. 


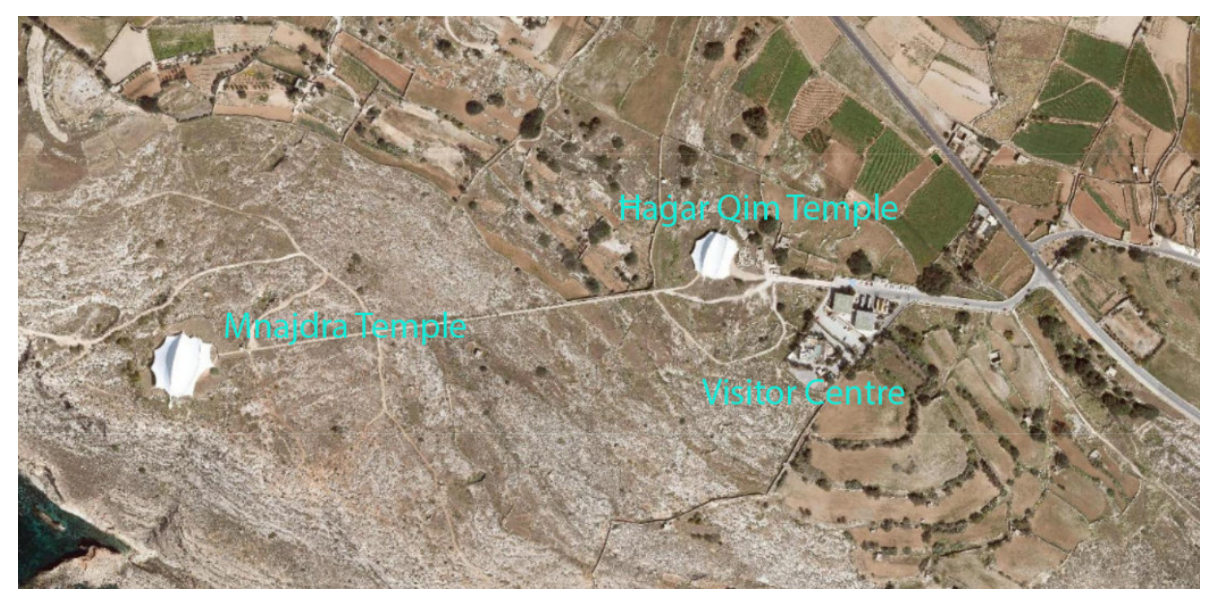

Figure 3: Hagar Qim and Mnajdra Temples. (Source: http://geoserver.pa.org.mt/ publicgeoserver.)

\section{METHODOLOGY}

\subsection{Management plan}

A management plan for a cultural heritage site is a document that combines general strategies and polices with specific goals that relate to the significance and setting of the site [5]. This type of report is done for each and every cultural heritage site around the world. When comparing one report with another, it can be noted that the scope of each is the same. In general a report usually consists of a site description and documentation, site assessment and analysis, management context, site significance and values, conditions, risks and key issues, visions, aims and policies, strategies, actions and plan implementation.

Three international examples of a management plan are:

1) The Republic of Tajikistan - Central Asia [6].

2) Qusayr 'amra site management plan - Eastern Jordan [7].

3) Pasargadea management plan - Iran [8].

The section of the management plan dealing with the conservation of the site provides a holistic framework for decisions about conserving and, sustainable enjoyment of the site. One aspect of the management plan is in fact on how to best preserve the site while at the same time allowing the public to enjoy it. Example in the management plan called "The Republic of Tajikistan" in Central Asia it states that "the plan to increase the number of visitors has taken that issue into account. There will not be any visits without a guide, and moreover of a trained guide, featuring a guided tour in which the specific facets of site preservation are presented and explained" [6]. Hence for this particular site people will enjoy but with guidance.

Heritage Malta employs professionals with different areas of expertise. Some are architects, others scientists, others curators, archaeologists, accountants, designers, etc. that get together in order to make a project a success. However, before actually starting to work on any kind of project, it is the curator's task to formulate a management plan. During this process, the curators consult a number of different stakeholders that include government 
departments and agencies, non-governmental organisations, interested parties and the public. The wider the range of stakeholders being consulted the better. This is always beneficial in every management plan that is done. The Pasargadea management plan in Iran in fact shows a list of over ten (10) different stakeholders such as architects, structural engineers, tourism organisations, natural resource organisations, cultural heritage organisations, historians, archaeologists, conservators etc... that were consulted [8].

Once the management plan is approved, it is then of utmost importance, that everyone including the public abides by it. One aspect that can be determined from the plan, which is relevant to this paper, is whether a museum for visitors is adequate for such a site or not or whether the museum can be located within the site or must be built away from the historical site.

In a good number of sites managed by Heritage Malta, one of its main missions is to weigh all possible risks indicated in the management plan, in order to be able to develop a historical place into a museum for the public to enjoy while still preserving it for future generations. If the nature of the site permits the constant presence of visitors, the centre must then be designed in such a way to accommodate visitors but also staff members.

\subsection{Accessibility to cultural heritage}

\subsubsection{What is accessibility? Is it only limited to physical access?}

Cultural heritage, in both tangible and intangible forms, is found across the environment. Tangible heritage can take the form of features within structures, single buildings or entire territories, movable or immovable items. Such sites are given value and are considered significant by the people who experience them - individually but also collectively, as part of a community. Therefore, accessibility to cultural heritage sites potentially increases their importance to communities and, as part of their community, it is individuals who determine this "value - accessibility" interdependence. Naturally, elements of cultural heritage are not equally accessible; the different parameters of each site are to be studied individually depending on the circumstances [9].

Accessibility to heritage sites is necessary to allow the public to explore, experience, and thus renew their heritage. Even though accessibility should not only be limited to physical access, but also intellectual and experiential access [10], nothing beats the actual visit to a heritage site. Hence, the dilemma arises of how to identify possible and acceptable degrees of physical access without compromising the monument itself.

\subsubsection{What makes one decide whether a monument should be accessible or not?}

Cultural heritage is not just a set of cultural objects or traditions from the past. It is also the result of a selection process: a process of memory and oblivion that characterizes every human society constantly engaged in choosing - for both cultural and political reasons - what is worthy of being preserved for future generations and what is not [11]. This affects the level of accessibility that can be given to a site while mitigating possible risks to its protection. Sociocultural values are attached to an object, building or place because it holds meaning for people or social groups due to its age, beauty, artistry, or association with a significant person or event or otherwise contributes to processes of cultural affiliation.

"The assessment of values and the understanding of threats at the site allowed the definition of a vision statement and of policies addressing long term conservation, presentation, and community engagement at Qusayr 'Amra" [7].

Different sociocultural values can sometimes overlap. For example, a church can have spiritual or religious significance as well as historical value (the history of generations 
worshipping in the church and playing a role in the development of the surrounding community). Other values may include political value (the use of heritage to build or sustain civil relations, state meetings held by credentials committee, governmental legitimacy, protests or ideological causes) and social values, which may include the use of a site for social gatherings such as celebrations, markets, or picnics. These are activities that do not necessarily capitalize directly on the historical values of the site but, rather, on the public/shared-space qualities [12].

The Maltese Government has set up Heritage Malta way back in 2002 [13] to preserve such monuments reflecting on society's needs and to create the best conditions in which to allow the public to engage with the sites. At the end of the day, it is the public that determines which of the site's values will be deemed more important for the community [14].

Therefore, Heritage Malta attempts to impart on its various publics, starting from a very young age, the importance of cultural heritage and that heritage belongs to everyone to enjoy. It does this by organising a range of different events and activities, from simple open days to lectures, thematic events and artistic events where artists interact with heritage to create original performances and/ or works of art.

\subsection{Involving the public}

Heritage is precious and non-renewable [15] and belongs to the community. The community has a responsibility to preserve its heritage, as stressed in the Amsterdam Declaration [16], not for its own sake but also that of its descendants [17]. Otherwise, part of "man's awareness of his own continuity will be destroyed" [18].

\subsubsection{What are the potential impacts and risks?}

It is good to involve the public in recognising the value of the site and explain the reasons and meaning of certain rules and regulations such as "do not touch", "do not take photos", "do not climb", etc. Considerable damage is very often caused by innocent touching. One touch may seem insignificant, but a million touches can seriously damage a monument. The tiny traces of moisture from a finger can easily strip away the patina of the monument, exposing it to other risks.

For example, when visitors use the walkway of Hagar Qim and Mnajdra or that of the Hal Saflieni Hypogeum, designed to take visitors through the site, some actually touch the monument, perhaps out of curiosity, since the walkway is fixed only a few centimetres away. Hence, it is very important to teach the public how to observe and recognise the state of conservation of a monument, in order to minimise their own impact on it and thus help preserve it for the future.

Another aspect that the public is not always aware of is that if any part of a monument is lost, then it means that it is lost forever and cannot be replaced. Once lost, the only way is to replace it with a replica. Unfortunately, no matter what kind of material and method of construction is used to restore a monument, the original effect and experience will never be attained. It will only serve as a symbol that keeps the memory of such a monument alive. The discovery of the Hal Saflieni Hypogeum during building activity, for example, was only reported to the authorities after construction works had been concluded. This resulted in permanent damage to the upper level of the site. Better awareness of heritage values at the time, may have contributed to better preservation of this part of the site.

Therefore, it is very important for agencies such as Heritage Malta to involve all members of society in a number of activities / events and to communicate information related to cultural heritage in order to change people's attitudes and engage their collaboration in 
protecting such sites. Letting the public know about the costs of restoration treatment and maintenance is also vital. Education value is also very important in every site in order to encourage the community to understand better the importance of such sites. "The educational value is one of Qusayr "Amra's key assets" [7] same as it is for our sites in Malta. It is only by involving people and making them aware that heritage is fragile and finite that their behaviour and attitudes towards cultural heritage can possibly improve.

\section{RESULTS}

\subsection{Society vis-a-vis historical sites}

"Facilities, services and infrastructures are of fundamental importance to allow a pleasant and appreciated visit to the site, and are thus a tool for appropriate communication of the site values" [7].

4.1.1 What solutions can be adopted to render cultural heritage accessible?

When preparing the management plan, one question that comes to mind is, whether or not a separate visitor centre is required for that particular site. It is very important to consider the impact of visitors on both the internal and external fabric of the heritage site. For no reason whatsoever the historical attraction can ever be compromised in order to accommodate visitors. Its' different uses must be identified, and ways should be found to allow all to take place without putting the site at risk. The historical place is always given priority over visitors, however a balance needs to be created between the conservation of the site and visitor access, since the public has also the right to visit and enjoy these jewels. If it is not possible to accommodate a visitor centre within the historical attraction, then there is always the option of locating it outside the monument but still close enough.

At Hagar Qim and Mnajdra, it was in fact decided to build a modern visitor centre just a few meters away from the prehistoric temples, since it was not possible to accommodate the needs required by visitors within the temples themselves. Choosing the location for the centre was not an easy task, since the sites are still surrounded by pristine landscape that still allow visitors to enjoy the sites in their landscape context. After careful consideration of possible options for the location of the centre, it was eventually built at the site of a carpark that was considered too big for the amount of visitors visiting the site. This ensured that there was no fresh impact on the landscape surrounding the site. A visitor centre can include but is not limited to a reception, an interpretation area, a shop, a cafeteria and other amenities, encouraging visitors to enter and spend some time in the building. These centres could also include displays of finds discovered in and around the sites themselves, to enable visitors to understand and appreciate the outstanding universal value of the sites. The profits made from both the shop and cafeteria help in maintaining and running of the site. Therefore, these should be located in areas that can be easily reached both, when entering and leaving the site.

On the other hand, at the Grandmaster's Palace in Valletta, the visitor centre is located within the palace itself, since the building is big enough to accommodate all the requirements and has enough rooms readily available for this purpose. The Grandmaster's Palace in Valletta also has other obligations, since it is still used for official functions such as hosting state visits, credential meetings and also houses the office of the president of Malta, making it the only office of the president, which is also open to visitors as an attraction. Therefore, the part of the palace that is used for official functions is presently manned by the staff from the office of the president who are permitted to use the building whenever needed. Heritage 
Malta's duty in this case is to provide the required spaces while at the same time protect and preserve the site for future generations.

It is good to keep in mind that a visitor centre does not only consist of a reception area, shop, cafeteria and public amenities, but could also include an office, staff room, kitchenette, store, switch room/server room etc... These essential facilities are required for the actual dayto-day running of the site. Therefore, one must also make sure that apart from fitting all the mentioned areas any services such as electrical, lighting, telephone, computers, security, plumbing, fire exits and equitable access are thought of and provided for.

One disadvantage of daily visitor access is the environmental impact on the monument itself, whether it is stone, wood, glass or any other kind of material. Therefore, the environmental conditions need to be monitored and kept stable - both for the historical site itself but also for the comfort of visitors. Some of the environmental conditions that are usually monitored are relative humidity, temperature, light levels, airborne pollutants (including dust and volatile substances) and pest and mould intrusions. Example in Qusayr Amra Jordan should the number of tourists "increase in the future, may indeed lead to the overcrowding of the main monument building, with all consequent environmental fluctuations and their impact on the conservation of the paintings" [7].

Passive design is always preferred to active. Therefore, where possible, the materials chosen to build the visitor centre are ones that make the building energy efficient. This can be easily done when the building is new but more of a challenge when the visitor centre is incorporated within the heritage monument itself. In such cases, one would then need to try to improve the environmental conditions of the site by changing or adding the skin layers of the building, making sure that no damage is caused to the historical part.

The visitor centre of the Hal Saflieni Hypogeum is modern but built above the monument. Heat loss and gain from the outer skin were controlled passively, by installing insulation boards both on the walls and on roof. This, however, had to be supplemented by an active system to manage the environmental conditions of the monument itself. The monument, being built of globigerina limestone (which is a very soft Maltese stone), is very susceptible to changes in temperature and relative humidity. Hence, an active heating, ventilation and air conditioning (HVAC) system was installed to be able to control the ambient environmental conditions of the monument. The globigerina limestone tends to flake and deteriorate when there are fluctuations of temperature and relative humidity, but when kept constant this does not take place, therefore prolonging the life of the monument for future generations. Over and above, to control further the environmental conditions, the Hypogeum has a restricted number of visitors per day, that is, during visiting hours (9 am to $5 \mathrm{pm})$ only ten (10) people per hour are allowed to enter the site.

Returning to Hagar Qim and Mnajdra, after a lot of brainstorming within the Scientific Committee for the Conservation of the Megalithic Temples - a multi-disciplinary team set up by the Maltese Government in 2000 - it was concluded that the environmental parameters were one of the main causes of the loss of material from the stone and infill, leading to structural problems and eventually to the collapse of more vulnerable areas of the Temples. The main factors identified were direct rain, direct insolation, salt, biological growth and wind related issues. This then led to the conclusion that most of these issues could be tackled, at least in part, by sheltering the sites. The proposal to erect a shelter initially raised a number of concerns about the impact of such an intervention, particularly those on aesthetic and contextual values of the site. However, in order to maximise reversibility, as well as minimise the impact on the surroundings, it was decided to erect in each case an open, lightweight tentlike structure where all attempts would be made to implement the principle of passive environmental control. Comprehensive environmental monitoring was and is still being 
carried out both before and after the shelter was erected. The general consensus is that, for Malta, "the investigations carried out so far indicate that the shelters seem to be an appropriate solution" [19]. The protective structures, in turn, also provide shelter to the visitors from sun, rain and wind.

Visitors inside museums and sites are always guided as to where is accessible and where is not. After studies are carried out and risks calculated, areas that are safe for visitors as well as areas where touching or brushing against could perhaps be permitted (in case of replicas, for example) are identified. The visitors' route is then defined by a group of people from different professions that work within Heritage Malta. Walkways, ropes as barriers, and signs are then designed and installed in order to formulate the route for everyone to follow. However, the method of installation on site is always a reversible one, meaning that anything, which is an addition to the original fabric of the site, can be removed without causing any damage, whenever required.

Another task that this agency has, is to calculate all possible risks in order to both conserve the monument and allow visitors to enjoy their experience as best as possible. A management framework that can be used for this task is the limits of acceptable change (LAC) model, which consists of identifying arbitrary measures of change that are considered tolerable on a site. The LAC framework is based on the assumption that change is always present and that any use by visitors leads to some change. This helps to identify which impacts and changes are acceptable, in order to manage the site and its visitors in a way that ensures that these limits are well kept. This makes it a flexible method, which allows for sustainable management by striving to maintain a balance between visitors and site needs. For this to be successful, however, ongoing monitoring is essential. Evaluation of management decisions and actions proposed are key elements in the success of site management that follows the LAC model [20].

\subsubsection{Is physical accessibility a right in all cases?}

For the Grandmaster's Palace, visitors are guided with signs and ropes in order to know their route. In areas where there is a risk of damage, a rope is used in order to keep visitors away from the area. In the staterooms of the Grandmaster's Palace, for example, there are rooms that visitors are only allowed to see from the outside, because the risk to damage the historical fabric is deemed to be greater than the experience that visitors would have by entering the room. It was in fact concluded that by having visitors looking at the staterooms from the outside would still give them the same effect.

It is important that the experience of the visitors is one that helps them feel part of the heritage monument by also interacting with the space. Interpretation facilities that may include information panels, showcases with artefacts, hands on stations and 3D experiences are of an essence and must be done by experts in the field, always keeping in mind that everything has to be reversible and that no harm is caused to the monument. In fact, all sites that can be visited include a virtual experience in order to inform visitors better on the history of the site while giving them a more immersive experience [21].

Sometimes, due to the nature of the site, it is very difficult to make it accessible for people with special needs unless major interventions are carried out. Such interventions are not always possible, particularly when the visitor centre is located within the monument. This makes the use of technology and virtual experiences of utmost importance as this may be the only access that these visitors get to the site. The use of $3 \mathrm{D} /$ virtual experiences are also essential in cases where access is difficult or limited due to lack of space. This is the case of the Hal Saflieni Hypogeum and in 2017, a 20-minute audio-visual experience was introduced for visitors who do not manage to purchase tickets to enter the site since it is usually fully 
booked two to three months in advance. Admittedly, this does not replace the full experience of the visitor if s/he had to go into the site itself. However, it does at least, give them an idea of what that experience would be. When compared to Qusayr Amra in Jordan, it can be clearly shown how advanced the Hal Saflieni Hypogeum is in terms of accessibility, since as stated in the management plan in 2014 they are only aware of the fact that it lacks proper disabled-friendly accesses - no solution was yet proposed [7].

\section{CONCLUSION}

Each site has its individuality and therefore requires an independent approach. Nonetheless, today the need to establish guidelines for planning accessibility to cultural heritage has increased. On one hand, this is related to the fact that our democratic society is increasingly recognising the diversity of human needs and respectively the opportunities of engaging with cultural heritage. On the other hand, the merging of new technical solutions in the information technology era provides countless alternatives for contemporary expression and interpretation. Therefore, Heritage Malta as the national agency for cultural heritage in Malta strives to preserve the sites for both present and future generations but at the same time empowers them to experience and enjoy their culture and makes sure that it delivers the needs of society [22].

\section{ACKNOWLEDGEMENTS}

The author wishes to thank Perit David Zahra, Head of Projects of the Heritage Malta Agency, for his dedication in reading the paper and pointing out relevant references and case studies. Furthermore, Ms Maria Elena Zammit, Principal Curator of the Prehistoric Sites, is thanked for proof reading the paper.

\section{REFERENCES}

[1] Heritage Malta, Who we are. http://heritagemalta.org/about-us/who-we-are/. Accessed on: 6 Jun. 2019.

[2] Heritage Malta, The Palace Armoury. http://heritagemalta.org/museums-sites/thepalace-armoury/. Accessed on: 6 Jun. 2019.

[3] Pace, A. et al., The Hal Saflieni Hypogeum (4000 BC-2000 AD), Midsea Books: Malta, 2000.

[4] Heritage Malta, Draft Management Plan for the Megalithic Temples of Malta, 2014.

[5] UNESCO, Manual for activities directed at UCH, 2017. www.unesco.org/new/en/ culture/themes/underwater-cultural-heritage/unesco-manual-for-activities-directedat-underwater-cultural-heritage/unesco-manual/conservation-management/sitemanagement-plan/.

[6] Dana, L.P., The Republic of Tajikistan. When Economies Change Paths, pp. 103-115, 2010.

[7] Palumbo, G. \& Atzori, A., Qusayr 'Amra Site Management Plan, pp. 30-38, 2014.

[8] Pasargadae Management Plan, 2002.

[9] Georgieva, D., The accessibility to cultural heritage as a key factor for sustainable development of territories, 2013.

[10] Sormoen, O., Accessibility to Cultural Heritage, Nordic Perspectives, 2009.

[11] Franchi, E., What is cultural heritage? www.khanacademy.org/humanities/art-historybasics/beginners-art-history/a/what-is-cultural-heritage. Accessed on: 6 Jun. 2019.

[12] Getty Conservation Institute LA, Assessing the Values of Cultural Heritage, Los Angeles. 
[13] Heritage Malta, Who we are. http://heritagemalta.org/about-us/who-we-are/. Accessed on: 6 Jun. 2019.

[14] ICCROM, Introducing Young People to the Protection of Heritage Sites and Historic Cities: A Practical Guide for School, p. 68, 2006.

[15] ICOMOS, Charter for the preservation of Quebec's Heritage (Deschambault Declaration), 1982, 2011. www.icomos.org/en/support-us/179-articles-enfrancais/ressources/charters-and-standards/192-the-deschambault-charter.

[16] ICOMOS, European Charter of the Architectural Heritage, 1975.

[17] Ruskin, J., The Seven Lamps of Architecture, Dover Publications: New York, 1989.

[18] Bostenaru Dan, M., The Cultural Value of the Built Heritage in the International Documents Dedicated to the Preservation of the Cultural Heritage, 2008. www.researchgate.net/profile/Maria_Bostenaru_Dan/publication/200038775_The Cultural_Value_of_the_Built_Heritage_in_the_International_Documents_Dedicated to_the_Preservation_of_the_Cultural_Heritage/links/0d50ae560eacbe9be-2e9e867. pdf.

[19] Cassar, J., Cefai, S., Grima, R. \& Stroud, K., Sheltering Archaeological Sites in Malta: Lessons Learnt, 2018.

[20] Heritage Malta, Ta' Hagrat and Skorba: Ancient Monuments in a Modern World, 2008.

[21] NSW Heritage Office, Just Because it's Old: Museums and Galleries in Heritage Buildings, 2004.

[22] Georgieva, D., The Accessibility to Cultural Heritage as a Key Factor for Sustainable Development of Territories, 2013. 